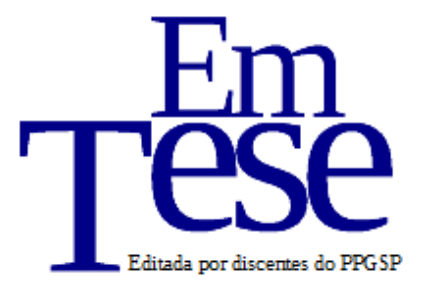

UFSC

PPG SP PROG RAMA DE

PÓS-GRADUAÇÃ̃O EM

Sociologia

Política

v. 12 , n. 2, ago./dez., 2015

\title{
Pedagogia das competências e ensino de sociologia: adesão e resistência nas diretrizes curriculares das regiões sul e sudeste
}

\author{
Ana Carolina Bordini Brabo Caridá ${ }^{1}$
}

\section{Introdução}

A obrigatoriedade do ensino de sociologia na escola média brasileira, em escala nacional, data de 2008. Alguns estados da federação já vinham oferecendo a disciplina desde a década de 1980, após a ditadura militar, o que se intensificou com a recomendação da Lei de Diretrizes e Bases da Educação Nacional (LDB, 1996)².

Em 1998 são publicados os Parâmetros Curriculares Nacionais (PCNs, 1998) onde constava que os saberes da sociologia e da filosofia poderiam estar presentes em outras disciplinas ou temas transversais. Este documento já apontava a necessidade de trabalhar com as três áreas de conhecimento das ciências sociais: sociologia, antropologia e ciência política.

O documento nacional mais recente, que norteia seu ensino, são as Orientações Curriculares Nacionais para o Ensino Médio: Ciências Humanas e suas Tecnologias (OCN's, 2006). Ele sugere caminhos metodológicos que o educador de sociologia deve percorrer para alcançar os objetivos propostos por seu plano de ensino. O documento sugere a abordagem sociológica em sala de aula a partir de temas, teorias ou conceitos, que seriam trabalhados articuladamente, mas não aponta quais conteúdos devem ser lecionados especificamente.

\footnotetext{
${ }^{1}$ Mestra em Sociologia Política pelo Programa de Pós-Graduação em Sociologia Política pela Universidade Federal de Santa Catarina (PPGSP/UFSC). Licenciada e bacharel em Ciências Sociais pela mesma instituição.

${ }^{2}$ Optei por não retomar a trajetória de inclusão/exclusão da disciplina de Sociologia no nível médio ao longo do século XX por entender que este tema já foi amplamente abordado em trabalhos anteriores (CARIDÁ, 2009; CARIDÁ, 2014; CARVALHO, 2004; JINKINGS, 2007; MORAES, 2004).
} 
A presença disciplinar da Sociologia (e também da Filosofia) se fortalece com a lei federal $\mathrm{n}^{\mathrm{o}} 11.684$, de 2 junho de 2008. Esta lei altera o art. 36 da Lei n⿳⺈ 9.394, de 20 de dezembro de 1996, que estabelece as diretrizes e bases da educação nacional, para incluir a Filosofia e a Sociologia como obrigatórias nos currículos das três séries do ensino médio.

Após a obrigatoriedade em nível nacional, alguns estados da federação publicaram as diretrizes curriculares para o ensino de sociologia ${ }^{3}$. Neste artigo apresento uma análise dos documentos oficiais vigentes nas regiões Sul e Sudeste até o ano de 2014. Diferente das demais regiões do país, todas as Secretarias Estaduais de Educação possuem propostas curriculares que orientam o trabalho docente. Escolhi este recorte por entender que são nestes espaços que a reflexão acadêmica está mais fortalecida, e, mesmo assim, está ocorrendo um grande distanciamento entre universidade e escola para a elaboração e efetivação dos documentos analisados.

A ideia do artigo é discutir se esses documentos vão de encontro à pedagogia das competências ditadas pelos Parâmetros Curriculares Nacionais (PCN's, 1998), em que medida elas se aproximam de concepções críticas, contrapondo os modelos de currículo ditos neoliberais ou por outro lado se aproximam apenas da ciência de referência e não se referem a teorias educacionais.

A fim de pensar o currículo de sociologia, é interessante salientar que este se inscreve em um processo maior de organização curricular pautado atualmente, em grande medida, na chamada "pedagogia das competências". Este modelo curricular organiza os saberes escolares de modo a contribuir com o modus operandi contemporâneo.

A presença da sociologia neste momento é algo singular, visto que é a primeira vez na história do currículo brasileiro que a disciplina passa a figurar na grade curricular das escolas de ensino médio de forma massiva. É inédita a proximidade desta ciência dos jovens e adultos que cursam as escolas públicas e particulares do país.

\footnotetext{
${ }^{3} \mathrm{O}$ artigo é parte da dissertação de mestrado intitulada "Sociologia no Ensino Médio: diretrizes curriculares e trabalho docente" defendida em 2014 pelo Programa de Pós-Graduação em Sociologia Política da Universidade Federal de Santa Catarina (PPGSP/UFSC). Naquele momento analisei as propostas curriculares publicadas nas cinco regiões do país após a obrigatoriedade do ensino de sociologia em nível nacional. As diretrizes curriculares analisadas para a obtenção do título de mestra foram as dos estados do Rio Grande do Sul, Santa Catarina, Paraná, São Paulo, Rio de Janeiro, Minas Gerais, Espírito Santo, Alagoas, Ceará, Acre, Tocantins, Goiás, Distrito Federal e Mato Grosso (CARIDÁ, 2014).
} 


\section{Neoliberalismo e pedagogia das competências}

Traçando um plano histórico, pode-se dizer que apenas na década de 1980 foi possível a organização de professores e pesquisadores em torno do ensino das ciências sociais na educação básica, no contexto das lutas sociais pela democratização do país.

$\mathrm{Na}$ década de 1990 o país abre suas fronteiras e as políticas econômicas fundamentadas no neoliberalismo passam a fazer parte dos novos programas sociais, educacionais, trabalhistas, de saúde, emprego e etc. A política econômica defendida por Margareth Thatcher, no fim dos anos 1970, chega aos países da América Latina cujo período ditatorial haviam se encerrado, dando lugar a um sistema de diminuição do Estado nas esferas de cunho social. Os pressupostos da acumulação flexível precarizam o trabalho e diluem os avanços na legislação trabalhista conquistados nos anos anteriores ao período militar. Trata-se de uma política mundial que dita as regras para os países em desenvolvimento em todos os âmbitos e esferas da vida pública e privada.

Neste sentido, a educação passa a operar com um novo significado, com uma nova teoria pedagógica que sustenta os pressupostos da reestruturação produtiva, pautada em uma concepção ideológica que inverte o real e aliena o trabalhador não apenas do produto final de seu trabalho, mas de suas relações pessoais, familiares, de consumo, de trabalho, transcendendo a alienação do processo produtivo e a estendendo para todas as esferas e instituições sociais, como por exemplo, a escola:

A escola progressivamente aproximou-se do mundo das empresas por meio de cooperações de todos os tipos, e também por revisões na maneira de pensar os conteúdos de ensino, organizar os modos de transmissão dos saberes e de avaliá-los (...) A noção de competência contribui para modelar uma realidade social enquanto pretende justificá-la. (ROPÉ; TANGUY, 1997, p. 18-19)

No que se refere a pedagogia das competências como discurso oficial adotado pelas políticas educacionais no Brasil, pode-se dizer que o conceito foi inicialmente pensado por Philippe Perrenoud, sociólogo suíço, que na década de 1990, sintetizou o conceito corporativo a fim de facilitar os pressupostos pedagógicos vigentes na época. Para Perrenoud (1999) é papel da escola formar cidadãos aptos a entrada no mercado de trabalho e que estejam capacitados para operar determinadas funções dentro do modelo 
de acumulação flexível. Para tanto, é necessário que o próprio professor seja formado com base nestes critérios, para que ele possa ensinar os estudantes partindo da mesma concepção pedagógica, ou seja, trata-se de dizer que a pedagogia das competências deve estar presente em todos os âmbitos da formação profissional, seja ela superior, média ou fundamental. O autor afirma que o professor deve estar apto ao savoirfaire de sua profissão além de ter o conhecimento teórico necessário para ministrar suas aulas. Afirma que o conhecimento científico transmitido aos jovens não tem sentido se não for operacionalizado, se não for utilitário, e que conhecimento e competência são complementares.

Fazendo a critica ao modo como foi pensado o conceito de competência Ropé e Tanguy (1997) apontam que é necessário:

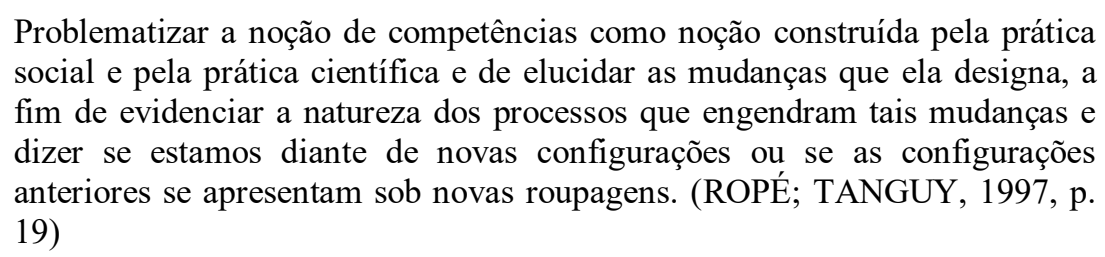

Ou seja, no que se refere a esta pesquisa propriamente dita, isto implica em analisar o currículo de sociologia no ensino médio como parte integrante do contexto neoliberal globalizado, pensando a formação humana no contexto educacional brasileiro neste século.

Pode-se dizer que as teorias pedagógicas se tornam senso-comum, são absorvidas pelos trabalhadores em educação e reproduzidas de forma automática (SAVIANI, 2008). Logo, se a proposta oficial está baseada na pedagogia das competências, os educadores formularão seus planejamentos didático-pedagógicos com base nesta teoria educacional. Ao contrário, os professores que tem acesso às teorias crítico-pedagógicas, poderão questionar esta abordagem e pensar propostas concretas de educação para a classe trabalhadora que estejam desvinculadas dos interesses reais da classe burguesa.

Newton Duarte (2010) afirma que o trabalho do professor nunca é neutro e que estas teorias pedagógicas travam lutas ideológicas que interferem no trabalho docente. As concepções neoliberais de educação permeiam o sistema escolar como um todo e 
estão presentes em toda a organização do ensino. Influenciam o currículo, o processo de ensino-aprendizagem e o trabalho docente.

Os currículos oficiais são pautados em determinadas teorias pedagógicas difundidas pelo discurso dominante e por sua ideologia. Propõem os conteúdos a serem ensinados pelos educadores moldando os interesses científico-pedagógicos aos novos padrões do mundo do trabalho globalizado. Estes currículos muitas vezes são pensados em conjunto com os educadores, outras são impostos de cima para baixo, empobrecendo o debate acerca da prática escolar, trazendo prejuízos ao ensino como um todo e ao trabalho do educador em particular.

\section{Diretrizes curriculares nacionais}

Os PCN's (1998) merecem inúmeras críticas, não apenas em relação a não obrigatoriedade da disciplina, mas também em relação ao tratamento das teorias das ciências sociais propriamente ditas. Ao focar na relação indivíduo/sociedade nota-se que a proposta é de cunho estritamente weberiano, visto que a ação individual é um conceito da sociologia compreensiva e os autores o tentam fragmentá-lo, como se pudessem alcançar os demais paradigmas clássicos:

De modo geral, pode-se afirmar que a matriz epistemológica weberiana vem predominando na construção dos currículos de Sociologia no Brasil. Os PCN (BRASIL, 1998) deixam explícita esta filiação teórica em várias passagens. Primeiramente, ao defender o conceito de relação social como "unidade elementar" da disciplina, apresentam os conceitos de "rede de relações sociais" e "interação social" com referência explícita à sociologia weberiana. Propõem, ainda, que se siga o modelo de estratificação social de Weber, baseando-se em sua abordagem dos conceitos de castas, estamentos e classes sociais. Por último, ao tratar do Estado, define-o como uma instância que "racionaliza a distribuição do poder legítimo dentro de uma nação", o que deixa novamente explícita sua filiação teórica weberiana. Esta opção fica clara não só por este repertório conceitual que o documento utiliza, mas também pela simplificação do pensamento de Marx e Durkheim, e pelo papel secundário atribuído a estes autores ao longo do texto. Por exemplo, ao tratar a categoria trabalho, indica a necessidade de abordá-la "para além do modelo marxista". Ressaltando a importância de não se naturalizar as relações sociais, o documento explicita que "nem em Durkheim encontramos essa aceitação" (grifos nossos). No primeiro caso, Marx é tratado como um autor a ser superado. No segundo, Durkheim é visto como um autor de menor porte, quase ingênuo. (SOUZA, 2013, p. 124)

É notável também a proximidade do documento com o discurso oficial burguês.

O mesmo institui, pela primeira vez, as competências e habilidades e serem 
desenvolvidos pela disciplina e não se aproxima do debate entre os educadores que fazem parte do cotidiano escolar.

Em 2002 foram publicados os PCN+, com o intuito de atualizar o documento anterior. O mesmo disserta sobre as competências e habilidades mencionadas nos PCNs, mencionando que estes dialogam com os três conceitos centrais das ciências sociais: trabalho, cultura e cidadania. Menciona a necessidade de trabalhar a pesquisa social a partir do cotidiano dos estudantes. Os conteúdos sociológicos não são abordados a partir de um viés crítico com relação ao mundo do trabalho. Não foca a questão no debate acerca do modo como a sociedade capitalista está organizada com seus conflitos e contradições. Não trata da transformação e revolução social, mas sim de mudanças sociais através da participação cidadã e democrática. Não questiona em momento algum o regime democrático da forma como ele está organizado politicamente e economicamente. Traz as questões que envolvem a sociedade capitalista a partir de um olhar de enquadramento neste processo e não de questionamento de suas bases materiais. Trata-se de um documento que norteia alguns conteúdos e temas interessantes para serem abordados em sala de aula, mas que deixa a desejar no que se refere ao seu caráter político-pedagógico e aos fundamentos mais amplos que envolvem as ciências sociais como um todo.

Posteriormente a este debate foram elaboradas as Orientações Curriculares Nacionais (OCNs, 2006). Estas não propõem um conteúdo programático definido a ser trabalhado com os estudantes, o documento sugere algumas formas de alcançar os objetivos propostos pela disciplina. Defende que a sociologia é o espaço de realização das ciências sociais no ensino médio e que não há uma discussão consolidada na área, conteúdos consagrados a serem trabalhados no ensino médio. Parte da desnaturalização e do estranhamento como fundamentos epistemológicos de seu ensino.

Como pressupostos metodológicos, elencam três caminhos a serem percorridos pelos educadores. A ideia é que os mesmos elaborem seus planos de ensino com foco em temas, conceitos e/ou teorias das ciências sociais. Recomenda que os professores optem por um dos recortes, tendo os outros dois como referenciais. Também traz a questão da pesquisa como ferramenta a ser trabalhada pelo educador. 


\title{
4. Diretrizes curriculares estaduais das regiões Sudeste e Sul
}

No que se refere às propostas de conteúdo publicadas nessas regiões, irei inicialmente trazer o estado do Espírito Santo para o debate. O documento intitula-se "Currículo Básico das Escolas Estaduais - Ensino Médio, área de Ciências Humanas" (2009). Nele constam alguns objetivos a serem percorridos pela disciplina, dentre eles:

\begin{abstract}
O objetivo da Sociologia é possibilitar ao aluno uma atitude investigativa/cognitiva e uma prática social voltadas para a autonomia e a participação, através da compreensão da construção social da realidade e da emergência de ações efetivas para transformá-la a cada dia, a cada escolha, a cada modo de saber e de fazer, a metodologia do ensino/aprendizagem passa necessariamente pela pesquisa e pela construção coletiva de conhecimentos e atitudes, a partir do alargamento das experiências e representações sociais cotidianas de todos os envolvidos no processo. Ou seja, o conhecimento precisa fazer sentido! E para isso precisa ser apropriado, contextualizado, negociado, confrontado, desconstruído e reconstruído. (ESPÍRITO SANTO, 2009, p. 95-96)
\end{abstract}

Como metodologias de ensino o documento elenca a necessidade de trabalhar com as mais variadas mídias, desde televisão até obras de arte. Foca também a pesquisa de campo nas comunidades e bairros onde as escolas se situam e aponta a necessidade de utilização de técnicas para a realização das entrevistas. Demarca a importância da produção de trabalhos pelos alunos a partir destas pesquisas, como por exemplo, vídeos, teatros, folhetins interativos e etc. Além disso, situa a importância de aulas expositivas dialogadas e o desenvolvimento de debates com as turmas.

O documento se divide em três eixos, cada um para uma série do ensino médio. São eles: "Ciência, Vida e Sociedade" (1' ano), "Trabalho, Cidadania, Fé, Vida e Sociedade" (2 ano) e "Cultura, Vida e Sociedade" ( $3^{\circ}$ ano). Ou seja, os eixos Vida e Sociedade perpassam as três séries. Podemos entendê-los como gerais para o ensino da sociologia. Desta forma, eliminando-os, temos os eixos: Ciência para o $1^{\mathrm{o}}$ ano, Trabalho, Cidadania e Fé para o $2^{\circ}$ ano e Cultura para o $3^{\circ}$ ano.

Na minha interpretação, poderia ser acrescido ao eixo Ciência a discussão sobre o Trabalho, pois o eixo elencado para o $2^{\circ}$ ano aglutina conceitos que devem ser trabalhados de forma separada (Trabalho e Cidadania), para que os estudantes possam se "acostumar" com o linguajar sociológico e possam diferenciar os conteúdos. Ainda me remetendo ao $2^{\circ}$ ano, penso que o debate posto a partir da palavra $F e ́$ é impreciso e 
se afasta da discussão sociológica e antropológica propriamente dita, pois o conceito a ser discutido deveria ser o de Religiosidade.

O documento também cita a valorização das especificidades regionais. É bastante sintético e repetitivo, apesar de ser um arquivo que contém todas as diretrizes para o ensino fundamental e médio, totalizando quase mil páginas.

Com relação à sociologia, esta proposta curricular se foca mais nas discussões que circundam a sociologia como ciência, a questão do Brasil como nação em relação ao mundo, aborda também os movimentos sociais, problematizando as identidades hegemônicas. No caso da antropologia, discute comunidade, religiosidade, cultura, identidade cultural e multiculturalismo. Não discute a ciência política.Interessante um documento propor um debate sem fundamentação teórica anterior. Como abordar temas como cidadania e movimentos sociais, sem antes discutir Estado, Poder e Política?

A fim de dar continuidade ao debate trago o documento de Minas Gerais intitulado "Sociologia - Proposta Curricular (Ensino Médio)" (2007). A proposta curricular aponta que não é tarefa da sociologia formar o cidadão crítico e que também se deve levar em consideração o fato de não estarmos formando sociólogos no ensino médio:

\begin{abstract}
Os principais objetivos deste documento são: primeiro, a apresentação e definição de temas e tópicos considerados fundamentais para o ensino da disciplina Sociologia na educação de nível médio e, segundo, sugerir uma "estratégia" para tal ensino, enfrentando um problema de dupla face, o de não cair na excessiva simplificação ou no equívoco pedagógico de querer formar o "cidadão critico" através da disciplina sociológica e, de outra parte, o de não reproduzir a orientação "academicista" peculiar à maioria dos Cursos de Sociologia no terceiro grau. Trata-se de uma tarefa nova para a área da Sociologia em nosso país mas que, embora difícil, já conta com algumas experiências esparsas e com textos que servem de referência para o nosso empreendimento. (MINAS GERAIS, 2007, p. 7)
\end{abstract}

É uma proposta que leva em consideração os documentos nacionais, PCN's e OCN's. Procura distanciar-se do senso comum, mostrando a diferença entre um problema social e um problema sociológico. Como no estado do Espírito Santo, também divide os conteúdos em eixos temáticos divididos para cada série. As características da disciplina são expostas no decorrer do texto referente ao eixo temático. A proposta do primeiro eixo é bastante completa e demarca inúmeras características que servem de base não só para sua temática, mas como para toda a proposta de conteúdos. 
Aqui ela também se assemelha ao estado discutido anteriormente, pois trabalha "A sociologia como Disciplina Científica Autônoma: conhecendo nosso mundo social" no $1^{\circ}$ ano do ensino médio. Traz Wright Mills para falar da construção do olhar sociológico, marca Anthony Giddens como um autor contemporâneo a ser estudado e aponta como exemplo do cotidiano o hábito de tomar uma xícara de café todas as manhãs assinalando a construção social e cultural contida neste costume.

Após se remeter ao sócio-cultural foca nas ações humanas, defendendo que apesar do contexto influenciar os hábitos sociais as pessoas são seres racionais e livres para fazerem suas próprias escolhas. Além de autores contemporâneos traz Durkheim e Weber, para falar de suicídio e do "espírito do capitalismo".

Ainda no decorrer do eixo temático explicita os objetivos que a disciplina deve percorrer e se mostra preocupada com a especificidade da sociologia frente as demais disciplinas. Demarca a importância da pesquisa sociológica realizada pelos estudantes, para que eles possam fazer a relação entre teoria e dados empíricos desnaturalizando o senso comum:

É importante, portanto, ter em mente que o caráter científico do conhecimento não elimina as tensões e diversidades das teorias que cohabitam e disputam entre - si a "melhor" e mais convincente explicação do comportamento, do fenômeno ou objeto que é focalizado pelos cientistas de uma mesma disciplina. A sociologia contemporânea pode ser descrita mais como um mosaico de teorias e métodos do que como um corpo integrado e compacto de conhecimento. (MINAS GERAIS, 2007, p. 14)

O segundo eixo temático propõe o debate acerca da "Análise Sociológica do Mundo Moderno: a Sociedade em que Vivemos" e traz os autores clássicos Durkheim, Weber e Marx:

\footnotetext{
Aquilo que Marx via como um traço essencial do mundo moderno - o trabalhador inteiramente separado dos meios de produção - Weber via como um sintoma de um processo mais abrangente: o de racionalização nas diferentes esferas da vida. Tratar da análise das principais características da sociedade moderna implica expor os estudantes a esta discussão. (MINAS GERAIS, 2007, p. 18)
}

Insiste na comparação entre Marx e Weber no decorrer do texto, como ambos entendem a modernidade e o advento do capitalismo. Sugere a discussão entre o tradicional e o moderno, movimento sociais, organizações não governamentais (ONG’s), associações comunitárias e sindicatos. 
No terceiro eixo, se remete "A abordagem sociológica de questões sociais no Brasil contemporâneo" e discute raça, gênero, criminalidade e sub-culturas juvenis; efeitos da raça sobre a estratificação social e a relação entre raça e mobilidade social; efeitos que a condição do gênero possui sobre o diferencial de salários no mercado de trabalho e etc.

As diretrizes curriculares de Minas Gerais para o Ensino de Sociologia se baseiam em temas e buscam pensar os problemas sociais advindos dos processos que envolvem as questões das desigualdades sociais, no caso da sociologia. Com relação aos conteúdos antropológicos, aborda os temas a partir dos conceitos de diversidade, identidade e gênero. Se aproximando da ciência política, aborda as discussões acerca da democracia e participação política.

O estado do Rio de Janeiro publicou, pós-obrigatoriedade em nível nacional, duas propostas. A primeira edição data de 2011 e os conceitos de "cultura, política e trabalho, eixos temáticos fundantes das Ciências Sociais, estavam distribuídos ao longo das três séries do Ensino Médio" (RIO DE JANEIRO, 2012, p. 03). Atualmente, o documento em vigor se intitula "Currículo Mínimo 2012 - Sociologia" (2012). Como mencionado no título, parte do conceito de currículo mínimo para estabelecer os conteúdos a serem trabalhados pelas disciplinas:

\footnotetext{
O Currículo Mínimo visa estabelecer harmonia em uma rede de ensino múltipla e diversa, uma vez que propõe um ponto de partida mínimo que precisa ainda ser elaborado e preenchido em cada escola, por cada professor, com aquilo que the é específico, peculiar ou the for apropriado. (...) O Currículo Mínimo apresentado busca fornecer ao educando os meios para a progressão no trabalho, bem como em estudos posteriores e, fundamentalmente, visa assegurar-lhe a formação comum indispensável ao exercício da cidadania. (RIO DE JANEIRO, 2012, p. 02).
}

Para a sua formulação apoiou-se nos PCN's e nas OCN's e contou com a contribuição dos professores da educação básica e do ensino superior. O documento aponta a necessidade de pensar um currículo específico para a sociologia a fim de fortalecer a disciplina no ambiente escolar:

\footnotetext{
A Sociologia aplicada no Ensino Médio, apesar de sua obrigatoriedade garantida pela LDB, precisa "inventar sua tradição", inclusive em relação ao reconhecimento de conteúdos fundamentais e um conjunto de habilidades e competências que sirvam como referências. Esse seria um passo importante na tarefa de legitimar a Sociologia no Ensino Médio, pois, como disciplina de
} 
obrigatoriedade ainda recente na grade curricular, ela ainda enfrenta obstáculos para sua consolidação definitiva, como o discurso tecnicista que insiste em questionar sua relevância, bem como a importância da reflexão e do senso crítico para o exercício da cidadania. (RIO DE JANEIRO, 2012, p. 03).

Os autores da proposta afirmam não concordar com a organização do currículo em habilidades e competências, mas ressaltam que o currículo mínimo é uma política educacional, logo, existem algumas normativas a serem seguidas. Assim, a contragosto, definem temas e elencam habilidades e competências para cada bimestre de cada série do ensino médio. Por exemplo, para o primeiro bimestre do $1^{\circ}$ ano elencam como habilidades e competências a partir do conteúdo "O conhecimento sociológico":

- Diferenciar os conceitos de senso comum e conhecimento científico e compreender a Sociologia como a ciência das relações sociais.

- Compreender o homem como ser social e a subjetividade individual como resultante da socialização.

- Compreender a relação entre o indivíduo e a sociedade, bem como as diferentes formas de sociabilidade. (RIO DE JANEIRO, 2012, p.6).

Como habilidades e competências para o segundo bimestre do $1^{\circ}$ ano a partir do conteúdo Cultura e diversidade:

- Identificar o homem como ser histórico e cultural e compreender a importância do conceito antropológico de cultura.

- Compreender os problemas decorrentes da visão etnocêntrica e relativizar as diferenças culturais.

- Compreender a dinâmica das mudanças culturais e sua relação com as transformações das sociedades. (RIO DE JANEIRO, 2012, p. 6).

A proposta curricular do estado é bastante enxuta com relação aos conteúdos das ciências sociais. Sociologicamente aborda o trabalho em suas relações sociais, consumo, comunicação de massa e formas de violência. Antropologicamente aborda os conceitos de cultura, diversidade e identidade, discutindo também o preconceito e a discriminação. Na ciência política, discute os conceitos poder, política, estado, democracia e participação política.

Apesar do Rio de Janeiro trazer uma proposta bastante concisa e sintética, tratase de um documento que se enquadra na história, explicando o porquê de seus pressupostos pedagógicos, demarcando a importância da presença da sociologia no ambiente escolar, processo ainda em fase de legitimação. O documento reflete o 
interesse dos professores e pesquisadores da área e se refere a determinação de conteúdos específicos para a disciplina.

No estado de São Paulo também foi publicado um documento bastante sintético, porém não com as mesmas qualidades do estado anterior. A "Proposta Curricular do Estado de São Paulo para a Disciplina de Sociologia" (2012) foi revisada e publicada sem levar em consideração os fundamentos político-pedagógicos que permeiam o trabalho com a sociologia na escola.

O documento menciona a proposta curricular elaborada no estado em 1986 pela Associação dos Sociólogos de São Paulo (ASESP), pioneira em elencar os conteúdos pertinentes ao ensino da sociologia.

As diretrizes curriculares do estado abrangem os conteúdos das três áreas das ciências sociais, pois entendem que a sociologia é o espaço de realização das ciências sociais na escola média. Seguem os fundamentos epistemológicos definidos pelas OCN's e discutem a Sociologia da Juventude de Mannheim e buscam pensar quem é o jovem que cursa o ensino médio público no país. Como no Rio de Janeiro também definem os conteúdos a partir de cada série do ensino médio, os dividindo por bimestre.

A diretriz curricular paulista trabalha os conteúdos a partir de temas e por dividilos em bimestres acabam se tornando extensas. Percebe-se a proximidade dos temas com relação às demais propostas já apresentadas e também a novidade no que se refere a temas como: aculturação, organização dos poderes, processo de desnaturalização e estranhamento da realidade, dentre outros.

Fazendo um comparativo da região Sudeste podemos perceber que os dois primeiros estados apresentados, Espírito Santo e Minas Gerais, possuem documentos similares no que se refere a forma como são organizados e fundamentados pedagógica e sociologicamente. Afirmo isto, pois, ambos se atrelam a concepções neoliberais de educação e de ciência social. Também se aproximam com relação a divisão dos conteúdos em eixos estruturadores para cada série do ensino médio.

As duas últimas diretrizes curriculares citadas, Rio de Janeiro e São Paulo, se assemelham no que se refere a organização dos conteúdos por série e por bimestres. Já com relação aos fundamentos pedagógicos a única proposta da região que se mostrou crítica à pedagogia das competências foi a do Rio de Janeiro. Mesmo estruturando os conteúdos com base neste conceito, os autores se posicionam politicamente e criticam o 
fato de terem que se enquadrar na política educacional estatal, a qual exige esta fundamentação teórica a priori. No caso do estado de São Paulo não há nenhuma crítica e nenhum alinhamento neste sentido.

Darei início a exposição acerca dos documentos oficiais da região Sul abordando o documento do Paraná intitulado "Diretrizes Curriculares da Educação Básica" (2008). É uma proposta curricular que serve de exemplo para todos os estados, pois abrange uma discussão teórica densa, não no que se refere a quantidade de conteúdos para serem ministrados aos alunos, mas sim pela completude com que aborda cada tema selecionado. Trata-se de um documento voltado exclusivamente ao ensino da sociologia e está organizado em mais de cem páginas. Foi pensado em conjunto com os professores da rede pública.

Em seu inicio trata da educação básica de modo geral, em seguida traz a história da sociologia, apontando as revoluções política (Francesa), social (Industrial) e científica (Iluminismo) como ponto de partida para a construção da ciência sociológica. Também trata da história da disciplina de sociologia no ensino médio paranaense. Por tratar-se de um caderno bastante extenso, pode ser entendido como uma espécie de apostila onde professores de outras áreas do conhecimento podem se inteirar sobre a disciplina ${ }^{4}$.

Aborda autores clássicos da sociologia como Comte, Durkheim, Marx e Weber e se pauta na sociologia crítica de Florestan Fernandes para pensar o trabalho docente com a disciplina. Aponta sugestões metodológicas e recursos didático-pedagógicos, ressaltando a importância das pesquisas de campo com os jovens do ensino médio.

O documento não explicita vinculação a pedagogia das competências. No decorrer da discussão teórica contribui para uma análise comparativa entre a sociologia no Brasil e o currículo de sociologia nas escolas de ensino básico:

A Sociologia como uma disciplina no conjunto dos demais ramos da ciência, especialmente das Ciências Sociais, não se produz de forma independente do trabalho pedagógico que a traduz como parte curricular nas escolas de níveis médio e superior. São intercomunicantes os caminhos dos estudos e pesquisas acadêmicas e as atividades curriculares no magistério. Fazer ciência mediante a reflexão acadêmica com base na pesquisa científica e esta

\footnotetext{
${ }^{4}$ Sabe-se que muitas vezes professores de outras áreas do conhecimento ministram a disciplina nas escolas públicas e particulares do país. Deste modo, entendo que as diretrizes curriculares do Paraná podem servir de apoio a estes profissionais, pois o documento pode ser considerado um mini-curso introdutório nesta área de conhecimento.
} 
alimentar a dimensão da formação do indivíduo são faces de um mesmo problema. É pensando uma e outra que se realiza a dimensão histórica da ciência e, desse modo, é aqui situada a Sociologia no Brasil. (PARANÁ, 2008, p. 41-42).

Os principais conteúdos curriculares para o ensino médio estão presentes nestas diretrizes curriculares. $\mathrm{O}$ documento articula conceitos clássicos das ciências sociais a temas contemporâneos, como violência e meio ambiente. Também nota-se o equilíbrio entre as três áreas das ciências sociais, não dando peso mais a uma ciência do que a outra. Mostra-se visível a interdisciplinaridade entre as três áreas das ciências sociais no que se refere a temas como cultura, trabalho e indústria cultural; a questão ambiental e os movimentos ambientalistas e etc.

Os professores do Paraná tiveram muito cuidado em construir a proposta, porém ela se torna repetitiva com relação às abordagens teórico-metodológicas sugeridas para os conteúdos. São pontos importantes para o desenvolvimento do trabalho docente, mas poderiam ter sido ditos uma vez apenas, e não serem abordadas em cada conteúdo particular. São elas:

Em Sociologia, devemos atentar especialmente para a proposição de problematizações, contextualizações, investigações e análises, encaminhamentos que podem ser realizados a partir de diferentes recursos, como a leitura de textos sociológicos, textos didáticos, textos jornalísticos e obras literárias. Esses encaminhamentos podem, também, ser enriquecidos se lançarmos mão de recursos audiovisuais que, assim como os textos, também são passíveis de leitura. A utilização de filmes, imagens, músicas e charges constitui importante elemento para que os alunos relacionem a teoria com sua prática social, possibilitando a construção coletiva dos novos saberes.

Cara à Sociologia, a pesquisa de campo, quando viável, deve ser proposta de maneira que articule os dados levantados à teoria estudada, propiciando um efetivo trabalho de compreensão e crítica de elementos da realidade social do aluno. Para que o aluno seja colocado como sujeito de seu aprendizado, fazse necessária a articulação constante entre as teorias sociológicas e as análises, problematizações e contextualizações propostas. Essa prática deve permitir que os conteúdos estruturantes dialoguem constantemente entre si e permitir, também, que o conhecimento sociológico dialogue com os conhecimentos específicos das outras disciplinas que compõem a grade curricular do Ensino Médio. (PARANÁ, 2008, p. 107 a 111).

Encerro as discussões sobre o Paraná e agora me remeto ao estado do Rio Grande do Sul a partir do documento intitulado "Referencial Curricular - Lições do rio Grande, Ciências Humanas e suas Tecnologias" (2009). É uma proposta curricular baseada nos PCN's e nas OCN's, vinculada claramente a pedagogia das competências. O documento se remete ao desenvolvimento humano sustentável e equitativo, como 
proposta da UNESCO (Organização das Nações Unidas para a Educação, a Ciência e a Cultura), e se mostra bastante preocupado com as questões centrais para os jovens, para, a partir delas, pensar os temas que podem ser trabalhados em sala. Aponta a necessidade de construirmos uma "Cultura da Paz":

\begin{abstract}
Trata-se de construir globalmente uma cultura que respeite todos os direitos individuais, que se empenhe em prevenir conflitos e que se comprometa com a solução das novas ameaças não militares para a paz e para a segurança, como a exclusão, a pobreza extrema e a degradação ambiental. A "Cultura de Paz", em síntese, tem por objetivo básico resolver os problemas por meio do diálogo, da negociação e da mediação, de forma a tornar a guerra e a violência inviáveis. (RIO GRANDE DO SUL, 2009, p. 93).
\end{abstract}

Ou seja, não pensa o conflito como gerador de problemáticas sociológicas, o vê como danoso à sociedade, apontando a coesão como fator de solução dos problemas da contemporaneidade. Desta forma, se aproxima de concepções funcionalistas e compreensivas e se distancia da concepção materialista histórico-dialética.

Elenca três competências centrais para o estudo sociológico, ler, escrever e resolver problemas:

No que se refere ao desenvolvimento dessas três competências, este Referencial Curricular parte do princípio de que elas devem ser organicamente articuladas com os três eixos de competências, a serem contemplados pelo ensino de Sociologia no nível médio, quais sejam: representação e comunicação, investigação e compreensão e contextualização sociocultural.

O eixo de competência representação e comunicação objetiva o desenvolvimento por parte do aluno da compreensão da Sociologia como Ciência da Sociedade.

O eixo de competências investigação e compreensão tem por temas principais as questões da Cultura e da Diversidade Cultural, da Tolerância e da "Cultura da Paz".

O eixo de competências contextualização sociocultural objetiva o desenvolvimento por parte do aluno da compreensão do papel histórico das instituições sociais, políticas e econômicas, associando-as às práticas dos diferentes grupos e atores sociais, aos princípios que regulam a convivência em sociedade, à distribuição equitativa dos benefícios econômicos, aos direitos e deveres da cidadania e à justiça. (RIO GRANDE DO SUL, 2009, p. 95-96).

Neste sentido, acredito que os estudantes do ensino médio devem ter contato com todos os paradigmas clássicos e contemporâneos das ciências sociais, para que possam conhecer e se posicionar politicamente frente aos conteúdos estudados. Deixar 
que teorias clássicas sejam aprendidas pelos jovens impede que eles sejam autônomos em suas escolhas e papéis sociais, afinal a tarefa da sociologia é fazê-los entender suas biografias na história.

É possível visualizar que os gestores em educação que construíram esta diretriz curricular apontam a "Cultura da Paz" como conteúdo a ser estudado pelos jovens do ensino médio. No momento não tive acesso as diretrizes curriculares das outras disciplinas, mas penso que como eixo estruturador da proposta tal conteúdo deve ser discutido nas demais áreas das ciências humanas. Como conteúdo genérico e não como conteúdo sociológico o documento aponta um distanciamento entre a ciência propriamente dita e a transposição didática sugerida.

Por fim, trago as diretrizes curriculares de Santa Catarina. O documento intitulado "Proposta Programática do Ensino de Sociologia e Sociologia da Educação" (1998) foi um dos primeiros publicados no país e contou com a colaboração da professora da Universidade de São Paulo (USP), Heloísa Dupas Penteado, uma das primeiras acadêmicas a dar visibilidade ao ensino da sociologia em nível nacional.

Posteriormente, foi publicado o documento "Orientação Curricular com foco no que ensinar: Conceitos e conteúdos para a Educação Básica" (2011). Até o ano de 2013 ambos os documentos estiveram vigentes. O estado atualizou suas orientações curriculares em 2014 com o documento "Proposta Curricular de Santa Catarina: Formação Integral na Educação Básica" (2014). O material dilui as disciplinas e trabalha a partir de áreas do conhecimento com ênfase na pedagogia das competências.

Com relação a proposta de 2011, posso esboçar um pouco mais de sua construção, pois pude acompanhar parte deste processo. O Colégio de Aplicação (UFSC) tinha a disciplina de sociologia presente em sua grade curricular desde o início da década de 1990. A sociologia estava presente na antiga $8^{\text {a }}$ série do ensino fundamental e no $1^{\mathrm{o}}$ ano do ensino médio. Havia uma professora efetiva que a lecionava, a qual trabalhou na instituição por mais ou menos vinte anos ${ }^{5}$. Após a entrada da disciplina como componente curricular obrigatório esta professora apresentou ao Laboratório de Ensino Interdisciplinar em Filosofia e Sociologia (LEFIS - convênio entre SED/SC e UFSC) um planejamento de ensino contemplando todas as séries do

\footnotetext{
${ }^{5}$ No livro "Sociologia: conhecimento e ensino" (2012) a professora Silvia Leni Auras de Lima conta um pouco mais da sua trajetória no artigo "A sociologia no ensino fundamental e médio: relato de uma experiência".
} 
ensino médio. Este esboço foi discutido em uma oficina permanente no LEFIS por três anos e posteriormente discutido em cursos de capacitação com os professores da Secretaria Estadual de Educação de Santa Catarina (SED/SC). Assim, após anos de debate ele foi apresentado ao órgão competente, o qual fez algumas alterações, sem consulta prévia, e o documento foi publicado em conjunto com as demais áreas de conhecimento.

Pedagogicamente o documento de 1998 se vincula a teoria histórico-cultural de Vygotsky, fundamentada no materialismo histórico-dialético. Elenca as dificuldades e desafios que os professores enfrentam no cotidiano das escolas e aponta o método dialógico de Paulo Freire como caminho metodológico. Naquele momento muitos eram os professores de sociologia não formados na área, então o documento aponta isto como fato e esmiúça cada conteúdo para que os mesmos possam se basear. Um dos defeitos desta proposta curricular é o fato dela ser escrita em tópicos e não dissertada. Menciona que durante a apresentação da disciplina o professor deve questionar: o que é sociologia? O que é ciência? O que é sociedade? Para que serve estudar sociologia? Além de outros recursos didático-pedagógicos, como o livro de Paulo Meksenas (2001).

O documento de 2011 se refere as três séries do ensino médio e não divide os conteúdos por bimestre, como algumas propostas têm sido organizadas. No que se referem aos conteúdos, as questões do mundo do trabalho estão presentes no $1^{\circ}$ ano, em conjunto com os temas introdutórios da disciplina, o debate sobre cultura se inicia no $2^{\circ}$ ano, complexificando-o em sua relação com o trabalho, e os conteúdos que aproximam sociologia e ciência política presentes no último ano do ensino médio. Trata-se de uma proposta bastante coerente, com começo, meio e fim, onde os conteúdos estão concatenados de modo a fazer com que o aluno entenda as questões que envolvem o modo de produção capitalista e a relação indivíduo/sociedade neste contexto.

Fazendo um balanço geral da região Sul nota-se que, atualmente, os estados do Rio Grande do Sul e Santa Catarina se aproximam da pedagogia das competências em relação ao embasamento teórico-pedagógico de suas diretrizes. No caso de Santa Catarina nota-se um grande retrocesso, pois as propostas curriculares de 1998 e 2011 haviam sido amplamente debatidas no interior das escolas e da universidade. Todo esse trabalho foi desvalorizado e uma nova diretriz foi colocada em seu lugar, sem levar em consideração os aspectos desenvolvidos anteriormente e sem a contribuição dos 
professores e pesquisadores desta área de conhecimento. A proposta do Paraná continua sendo um exemplo de debate fecundo entre universidade e escola, mas, ainda assim pode ser revista, desde que os gestores em educação do estado levem em consideração o diálogo em conjunto com a universidade e a escola.

\section{Considerações finais}

Sintetizando o exposto, é possível afirmar que atualmente apenas dois estados presentes nas regiões Sul e Sudeste mantém suas diretrizes curriculares desvinculadas da pedagogia das competências, são eles: Paraná e Rio de Janeiro. As secretarias estaduais de educação do Rio Grande do Sul, Santa Catarina, Minas Gerais e Espírito Santo se aproximam claramente deste embasamento teórico-pedagógico. A proposta curricular de São Paulo não explicita aproximação a nenhuma teoria educacional, faz menção apenas as ciências sociais. Desta forma, fica claro o domínio metodológico das políticas neoliberais para a educação presente nestes documentos oficiais.

Com relação à sociologia como o espaço de ensino das três áreas das ciências sociais, notou-se que, os estados de Minas Gerais, Rio de Janeiro, São Paulo, Paraná, Rio Grande do Sul e Santa Catarina formularam documentos que expressam o ensino da sociologia, da antropologia e da ciência política. A ciência política não é citada apenas no documento do estado do Espírito Santo.

O debate em torno das três áreas de conhecimento vem se fortalecendo, mas ainda precisa conquistar espaço. Cabem aos cientistas políticos e aos antropólogos estas reivindicações e o amadurecimento das questões didático-pedagógicas para que essas ciências venham a se legitimar no ambiente escolar.

\section{Referências}

BRASIL. Ciências humanas e suas tecnologias. Conhecimentos de sociologia. In: Orientações curriculares nacionais para o ensino médio. Secretaria de Educação Básica.- Brasília, v.3, 2006, p. 101-133,.

BRASIL. Parte IV: Ciências Humanas e Suas Tecnologias. In: Parâmetros curriculares nacionais para o ensino médio. Secretaria de Educação Básica - Brasília, 1998. 
BRASIL. PCN+, Ensino médio, Ciências Humanas e suas tecnologias. In: Orientações educacionais complementares aos parâmetros curriculares nacionais. Secretaria de Educação Básica. - Brasília, 2000.

BRASIL. Lei de Diretrizes e Bases da Educação Nacional, 1996.

BRASIL. Lei que estabelece as diretrizes e bases da educação nacional, para incluir a Filosofia e a Sociologia como disciplinas obrigatórias nos currículos do ensino médio, 2008.

CARIDÁ, A.C. Ensino de Sociologia no nível médio: estudo exploratório baseado em concepções de professores e estudantes da Grande Florianópolis. Trabalho de Conclusão de Curso. Universidade Federal de Santa Catarina, 2009.

- Sociologia no ensino médio: diretrizes curriculares e trabalho docente. Dissertação de mestrado. Universidade Federal de Santa Catarina. Florianópolis, 2014.

CARVAlHO, L. M. G. de. A Trajetória Histórica da Luta Pela Introdução da Disciplina de Sociologia no Ensino Médio no Brasil. In: Sociologia e Ensino em Debate: Experiências e Discussão de Sociologia no Ensino Médio. CARVALHO, L. M. G. de (Org.). Ijuí: Editora Unijuí. 2004, p. 17-60.

DUARTE, N. O debate contemporâneo das teorias pedagógicas. In: Formação de professores: limites contemporâneos e alternativas necessárias. São Paulo: Editora UNESP, 2010.

ESPIRITO SANTO. Secretaria de Educação. Currículo Básico das Escolas Estaduais - Ensino Médio, área de Ciências Humanas. Vitória, 2009.

JINKINGS, N. Ensino de Sociologia: particularidades e desafios contemporâneos. In: Revista Mediações, v.12, n.1, Londrina, 2007.

LIMA, S. L. A. A sociologia no ensino fundamental e médio: relato de uma experiência. In: Sociologia: conhecimento e ensino. Florianópolis: Em Debate, 2012.

MEKSENAS, P. Aprendendo sociologia: a paixão de conhecer a vida. São Paulo: Edições Loyola, 2001.

MINAS GERAIS. Secretaria de Educação. Sociologia: proposta curricular Ensino Médio. Belo Horizonte, 2007.

MORAES, A. C. O Veto de FHC: o Sentido de um Gesto. In: Sociologia e Ensino em Debate: Experiências e Discussão de Sociologia no Ensino Médio. CARVALHO, L. M. G. (Org.). Ijuí: Editora Unijuí. 2004, p. 105-111.

PARANÁ. Secretaria de Educação. Diretrizes curriculares de Sociologia para o ensino médio. Curitiba, 2008. 
PERRENOUD, P. Construir as competências desde a escola. Porto Alegre: Artes Médicas Sul, 1999.

RIO DE JANEIRO. Secretaria de Educação. Currículo mínimo 2012: Sociologia. Rio de Janeiro, 2012.

RIO GRANDE DO SUL. Secretaria de Educação. Lições do Rio Grande: referencial curricular - Ciências Humanas e suas Tecnologias. Porto Alegre, 2009.

ROPÉ, F. TANGUY, L. Saberes e competências: o uso de tais noções na escola e na empresa. Campinas: Papirus, 1997.

SANTA CATARINA. Secretaria de Educação. Proposta Curricular de Santa Catarina: formação integral na educação básica. Secretaria do Estado da Educação de Santa Catarina. Florianópolis, 2014.

Secretaria de Educação Proposta Programática do Ensino de Sociologia e Sociologia da Educação. Florianópolis, 1998.

Secretaria de Educação. Orientação curricular com foco no que ensinar: Conceitos e conteúdos para a Educação Básica. Florianópolis, 2011.

SÃO PAULO. Secretaria de Educação. Proposta Curricular do Estado de São Paulo para a Disciplina de Sociologia. São Paulo, 2009.

SAVIANI, D. Pedagogia Histórico-Crítica. Campinas: Autores Associados, 2008.

SOUSA, F. P. (org.). Sociologia: conhecimento e ensino. Florianópolis: Em Debate, 2012.

SOUZA, D. C. C. O ensino de Sociologia e a pedagogia histórico-crítica. Revista HISTEDBR, n. 51,Campinas, 2013. 


\title{
Pedagogia das competências e ensino de sociologia: adesão e resistência nas diretrizes curriculares das regiões sul e sudeste
}

Resumo: $O$ artigo analisa as diretrizes curriculares concernentes ao Ensino de Sociologia publicadas pelas secretarias estaduais de educação dos estados do Rio Grande do Sul, Santa Catarina, Paraná, São Paulo, Rio de Janeiro, Minas Gerais e Espírito Santo, até o ano de 2014. Busca refletir se os documentos oficiais se alinham a pedagogia das competências ou se representam resistência ao discurso oficial dominante. Além disso, realiza um balanço dos conteúdos das ciências sociais presentes nas propostas curriculares, apontando a presença da sociologia, antropologia e ciência política como objeto de ensino nas escolas.

Palavras-chave: Ensino de Sociologia; Diretrizes curriculares; Pedagogia das competências

\section{Sociology teaching and pedagogy skills: adhesion and resistance in the curriculum guidelines of the south and southeast}

\begin{abstract}
This paper analyzes the curriculum guidelines concerning Sociology Teaching published by state education departments in the states of Rio Grande do Sul, Santa Catarina, Paraná, São Paulo, Rio de Janeiro, Minas Gerais and Espirito Santo, until the year of 2014. It seeks to bethink if the official documents are align to the pedagogy skills or if they represent resistance to the dominant official argument. In addition, it performs an assessment of the Social Sciences curriculum proposals present in the content, indicating the presence of Sociology, Anthropology and Political Science as an educational object in schools.
\end{abstract}

Keywords: Sociology Teaching; Curriculum guidelines; Pedagogy skills

Recebido em: 26 de julho de 2015.

Aceito para publicação em: 06 de outubro de 2015. 